\title{
Effects of carbon dioxide therapy on the healing of acute skin wounds induced on the back of rats ${ }^{1}$
}

\author{
Maria Vitória Carmo Penhavel', Victor Henrique Tavares Nascimento"I, Eliana Ferreira Ribeiro Durães ${ }^{\mathrm{III}}$, Fabiana Pirani \\ Carneiro $^{\text {IV }}$, João Batista de Sousa ${ }^{\mathrm{V}}$ \\ IGraduate student, School of Medicine, University of Brasilia(UnB), Brasilia-DF, Brazil. Acquisition and interpretation of data, technical procedures, \\ statistical analysis, manuscript writing.

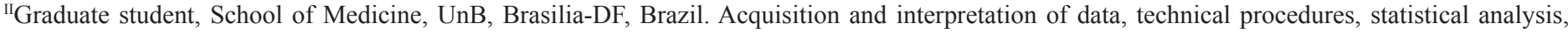 \\ critical revision.

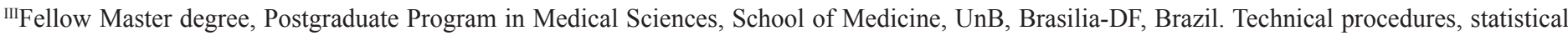 \\ analysis, interpretation of data, critical revision. \\ ${ }^{\text {IV }} \mathrm{PhD}$, Associate Professor of Pathology, School of Medicine, UnB, Brasilia-DF, Brazil. Macroscopic and histopathological examinations, interpretation \\ of data, critical revision. \\ ${ }^{\mathrm{v}} \mathrm{PhD}$, Associate Professor of Surgery, School of Medicine, UnB, Brasilia-DF, Brazil. Intellectual and scientific content of the study, design the \\ protocol, technical procedures, interpretation of data, manuscript writing, critical revision.
}

\section{ABSTRACT}

PURPOSE: To evaluate the healing effect of carbon dioxide therapy on skin wounds induced on the back of rats.

METHODS: Sixteen rats underwent excision of a round dermal-epidermal dorsal skin flap of $2.5 \mathrm{~cm}$ in diameter. The animals were divided into two groups, as follows: carbon dioxide group - subcutaneous injections of carbon dioxide on the day of operation and at three, six and nine days postoperatively; control group - no postoperative wound treatment. Wounds were photographed on the day of operation and at six and 14 days postoperatively for analysis of wound area and major diameter. All animals were euthanized on day 14 after surgery. The dorsal skin and the underlying muscle layer containing the wound were resected for histopathological analysis.

RESULTS: There was no statistically significant difference between groups in the percentage of wound closure, in histopathological findings, or in the reduction of wound area and major diameter at 14 days postoperatively.

CONCLUSION: Under the experimental conditions in which this study was conducted, carbon dioxide therapy had no effects on the healing of acute skin wounds in rats.

Key words: Wound Healing. Carbon Dioxide. Skin. Rats. 


\section{Introduction}

Wound healing consists in a coordinated cascade of cellular and molecular events that interact to allow tissue repair. Tissue injury triggers healing and initiates a series of temporally overlapping phases, including inflammation, new tissue formation, and tissue remodeling. Immediately after injury, the repair process is initiated by the action of a number of growth factors, cytokines, and products released from platelets and injured blood vessels. After the formation of the blood clot, inflammatory cells invade the wound tissue and exert functions of protection against contaminating microorganisms, being also an important source of growth factors and cytokines, which initiate the proliferative phase of wound healing. The proliferative phase starts with the migration and proliferation of keratinocytes at the wound edge and is followed by multiplication of dermal fibroblasts in the neighborhood of the injured tissue. Subsequently, fibroblasts begin to produce large amounts of extracellular matrix. Still in the proliferative phase, the granulation tissue is formed, name given by the granular appearance due to the presence of newly formed capillaries, which are essential for the repair process. Finally, a transition from granulation tissue to mature scar occurs, characterized by continued collagen synthesis and degradation. The scar tissue is mechanically insufficient and lacks epidermal appendages $^{1,2}$.

Since ancient times, man has tried to interfere in the tissue repair process. In recent decades, much effort has been devoted to identify substances and techniques in wound management which are able to promote healing. The search for substances with angiogenic activity has also been enhanced because of their great potential for clinical application. However, due to the high prevalence of complicated chronic ulcers, associated with organic diseases and disorders, wound healing remains a challenging clinical problem ${ }^{3}$.

The controlled injection of carbon dioxide $\left(\mathrm{CO}_{2}\right)$ or $\mathrm{CO}_{2}$ therapy has been used as a simple, safe, biocompatible, low-cost treatment option for wound management. $\mathrm{CO}_{2}$ therapy requires a portable device that enables subcutaneous application of $\mathrm{CO}_{2}$ for therapeutic purposes ${ }^{4}$.

The percutaneous route was the first to be used by means of $\mathrm{CO}_{2}$-enriched water baths to treat peripheral vascular diseases ${ }^{5}$. Injections of $\mathrm{CO}_{2}$ in the skin and adipose tissue have been widely used in aesthetic medicine with good results ${ }^{6-8}$. Studies have demonstrated that $\mathrm{CO}_{2}$ plays a role in the recovery of granulation tissue in chronic venous insufficiency ulcers ${ }^{9}$, and stimulates granulation in acute and chronic ulcers ${ }^{10}$.
The search for better clarification about the healing process and the factors able to modify it is of fundamental importance for daily surgical practice. Therefore researchers remain extremely committed to the study of healing in different experimental models ${ }^{11-13}$.

This study aimed to evaluate the healing effect of $\mathrm{CO}_{2}$ therapy on skin wounds induced in rats.

\section{Methods}

All experiments and procedures were carried out in accordance with the ethical principals involving animals in research defined by the Brazilian College for Animal Experimentation (COBEA), affiliated with the International Council for Laboratory Animal Science, and conformed to the Brazilian guidelines involving animals in research (Federal Law No. 6638 of 1979). The study was approved by the Institutional Animal Care and Use Committee of University of Brasilia, School of Medicine (protocol no. 52439/2011).

Sixteen adult male Wistar rats (Rattus norvegicus albinus, Rodentia mammalia), with initial body weight of 188 to $386 \mathrm{~g}$ and about 60 days of age, were used in the study. For seven days preoperatively, the animals were housed individually in home cages, maintained on a 12:12 light/dark cycle at room temperature and humidity, and had free access to water and specific chow (Purina $^{\circledR}$, Labina Ltda., Campinas-SP, Brazil).

\section{Experimental design}

The animals were randomly divided into two groups of eight individuals each to receive either subcutaneous injections of $\mathrm{CO}_{2}$ on the day of operation and at three, six and nine days postoperatively $\left(\mathrm{CO}_{2}\right.$ group) or no postoperative wound treatment (control group). All animals were killed on day 14 after surgery.

\section{Surgical procedure}

The animals were anesthetized with xylazine hydrochloride $(10 \mathrm{mg} / \mathrm{kg}$ body weight $)$ and ketamine hydrochloride (75 mg/kg body weight) intramuscularly. All surgical procedures were performed by same team.

After an adequate level of anesthesia was obtained, the animals were fixed in the prone position on a surgical board. Before surgical intervention, an area on the dorsal region of each rat was shaved and aseptically prepared with $2 \%$ chlorhexidine gluconate. All animals in both groups underwent the same surgical procedure. The center of the shaved area was previously demarcated with a dermatological metallic punch of $2.5 \mathrm{~cm}$ in diameter, and the 
excision of the skin flap was completed using a scalpel (Figure 1). Hemostasis was achieved by digital compression of the bleeding point with gauze. Then, animals in the experimental group received $\mathrm{CO}_{2}$ injected subcutaneously into the wound edge by inserting the needle directed toward the center of the wound (Figure 2). Animals in the control group received no postoperative wound treatment.

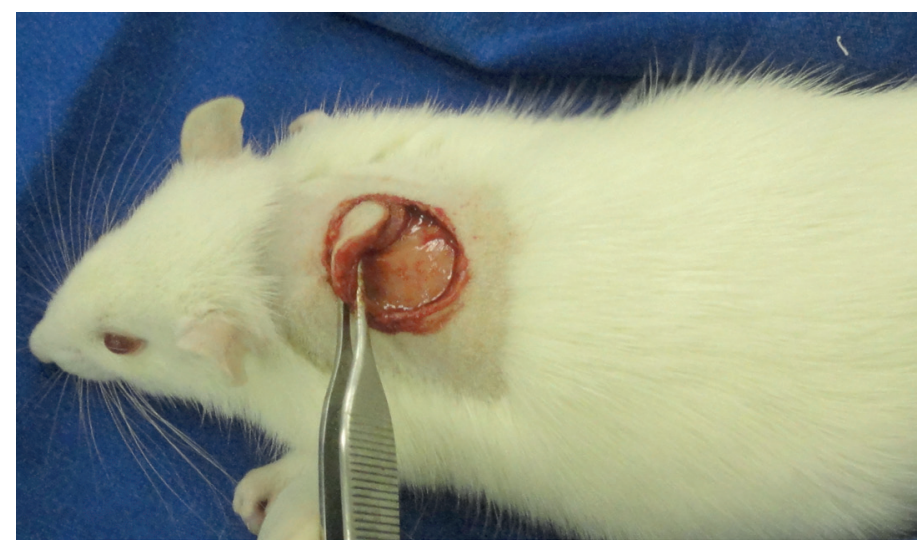

FIGURE 1 - Skin excision. Detail of the "punched-out" area, which was resected respecting the muscle layer.

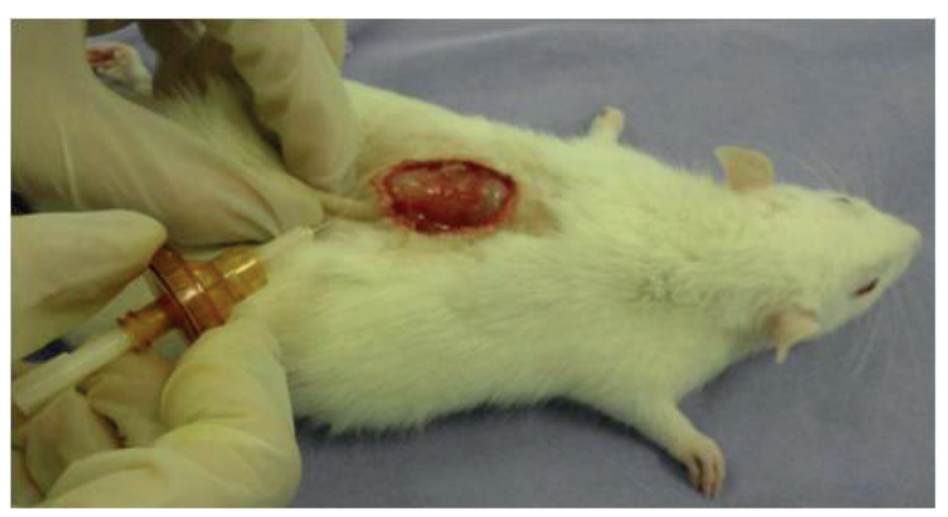

FIGURE 2 - Carbon dioxide $\left(\mathrm{CO}_{2}\right)$ therapy. Subcutaneous injection of $\mathrm{CO}_{2}$ into the wound edge, with the needle directed toward the center of the wound.

$\mathrm{CO}_{2}$ therapy was performed again at three, six and nine days postoperatively in the experimental animals. All animals, including control rats, were previously anesthetized on the days mentioned above. Neither group received occlusive dressing after application of treatment. At the end of the procedures, the animals were placed back in their respective cages under the same preoperative conditions.

\section{Postsurgical wound progression}

With the animals fixed on the surgical board, minor and major wound diameters were measured using calipers for comparison with the standard initial measurement. At this moment, wounds were photographed using a digital camera. This procedure was performed on the day of operation and at six and 14 days postoperatively. The images were transferred to Image ${ }^{\circledR}$ software and, after outlining the wound boundary using the polyline method (demarcation of all points of the wound), all images were analyzed for wound area and major diameter.

\section{Collection of material for analysis}

On the 14th postoperative day, all 16 animals were anesthetized with ketamine and xylazine intramuscularly. Then, a dorsal block containing the wound and the underlying muscle layer was resected. The animals were killed with a lethal dose of thiopental intraperitoneally $(25 \mathrm{mg} / \mathrm{kg})$. The specimens were fixed in formalin for histopathological analysis.

\section{Histopathology}

For histopathological analysis, paraffin-embedded specimens were stained with hematoxylin and eosin and examined under an optical microscope. The amount of collagen, fibroblasts, and polymorphonuclear and mononuclear infiltration was analyzed and graded on a scale of 0 to 3 , with 0 indicating absence, 1 mild amount, 2 moderate amount, and 3 marked amount of the analyzed parameter. Newly formed vessels were quantified in five high-power fields. The presence or absence of re-epithelialization, foreign body, abscesses or hair follicles in the scar tissue were also documented.

\section{Statistical analysis}

Data were analyzed using SigmaStat $^{\circledR}$ version 3.5. Wound areas and major diameters in experimental and control groups, on each experimental day, were compared using one-way analysis of variance (ANOVA). Fisher's exact test and the chisquare test were used to evaluate histological variables. The level of significance was set at $\mathrm{p}<0.05$.

\section{Results}

\section{Wound measurements}

A comparison of wound areas between $\mathrm{CO}_{2}$ and control groups, on day 0 and postoperative day 6 , showed no statistically significant difference $(\mathrm{p}=0.220$ and $\mathrm{p}=0.090$, respectively), although on postoperative day 6 the $\mathrm{CO}_{2}$ group showed a mean wound area smaller than that of controls. On postoperative day 14 , there was also no significant difference in wound area between groups $(\mathrm{p}=0.157)$ (Table 1$)$. 
TABLE 1 - Wound area $\left(\mathrm{cm}^{2}\right)$ in control and carbon dioxide $\left(\mathrm{CO}_{2}\right)$ groups.

\begin{tabular}{llll}
\hline $\begin{array}{l}\text { Experimental } \\
\text { day }\end{array}$ & $\begin{array}{l}\text { Control }(\mathbf{n}=\mathbf{8}) \\
\text { Mean } \pm \text { SD }\end{array}$ & $\begin{array}{l}\mathbf{C O}_{2}(\mathbf{n}=\mathbf{8}) \\
\mathbf{M e a n} \pm \mathbf{S D}\end{array}$ & $\mathbf{p}$ \\
\hline 0 & $4.17 \pm 0.88$ & $3.73 \pm 0.45$ & 0.200 \\
6 & $1.69 \pm 0.52$ & $1.31 \pm 0.29$ & 0.090 \\
14 & $0.04 \pm 0.04$ & $0.08 \pm 0.06$ & 0.157 \\
\hline
\end{tabular}

$\mathrm{SD}=$ standard deviation

Regarding the measurement of wound major diameter, there was no statistically significant difference between groups on any experimental day.

The percentage of wound closure from day 0 to postoperative day 6 showed no statistically significant difference in the comparison between groups $(\mathrm{p}=0.182)$. However, a higher percentage of wound closure was observed in the $\mathrm{CO}_{2}$ group compared to the control group (64.8\% and 59.5\%, respectively).

\section{Microscopic evaluation}

Tables 2, 3 and 4 show the histological comparison between groups on postoperative day 14, revealing no statistically significant difference in any factor analyzed. Although not statistically significant, the number of neovessels in the $\mathrm{CO}_{2}$ group, as observed in high-power microscopic fields, was larger than that of controls (Figure 3).

TABLE 2 - Histological comparison between control and carbon dioxide $\left(\mathrm{CO}_{2}\right)$ groups on the 14th postoperative day.

\begin{tabular}{lllll}
\hline & \multicolumn{2}{l}{$\begin{array}{l}\text { Control } \\
\mathbf{n = 8}\end{array}$} & \multicolumn{3}{c}{$\begin{array}{l}\mathbf{C O}_{2} \\
\mathbf{n = 8}\end{array}$} \\
\cline { 2 - 5 } & Mean & Max/min & Mean & Max/min \\
\hline Collagen & 2.0 & $2 / 2$ & 2.0 & $2 / 2$ \\
Fibroblasts & 3.0 & $3 / 3$ & 3.0 & $3 / 3$ \\
Mononuclear & 2.0 & $2 / 2$ & 2.0 & $2 / 2$ \\
Polymorphonuclear & 2.0 & $2 / 2$ & 2.0 & $2 / 2$ \\
Epithelial hyperplasia & 1.4 & $2 / 1$ & 1.9 & $2 / 1$ \\
\hline
\end{tabular}

$\mathrm{CO}_{2} \mathrm{X}$ control, $\mathrm{p}=0.105$.
TABLE 3 - Histological comparison between control and carbon dioxide $\left(\mathrm{CO}_{2}\right)$ groups on the 14th postoperative day (2).

\begin{tabular}{lllll}
\hline & $\begin{array}{l}\text { Control } \\
\mathbf{n = 8}\end{array}$ & & $\begin{array}{l}\mathbf{C O}_{2} \\
\mathbf{n = 8}\end{array}$ \\
\cline { 2 - 5 } & Present & Absent & Present & Absent \\
\hline Hair follicle & 0 & 8 & 0 & 8 \\
Abscess & 0 & 8 & 0 & 8 \\
Foreign body & 8 & 0 & 8 & 0 \\
Epithelialization & 4 & 4 & 3 & 5 \\
\hline
\end{tabular}

TABLE 4 - Comparison between control and carbon dioxide $\left(\mathrm{CO}_{2}\right)$ groups - quantification of newly formed vessels on the 14 th postoperative day.

\begin{tabular}{llll}
\hline & $\begin{array}{l}\text { Control }(\mathbf{n}=8) \\
\text { Mean } \pm \text { SD }\end{array}$ & $\begin{array}{l}\mathbf{C O}_{2}(\mathbf{n}=\mathbf{8}) \\
\text { Mean } \pm \text { SD }\end{array}$ & p \\
\hline Vessel / field & $24.50 \pm 9.24$ & $37.87 \pm 20.12$ & 0.110 \\
\hline
\end{tabular}

$\mathrm{SD}=$ standard deviation

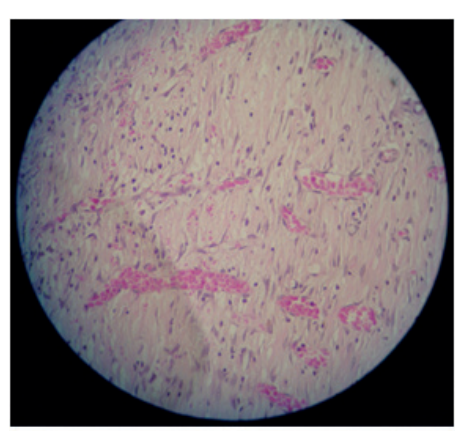

A

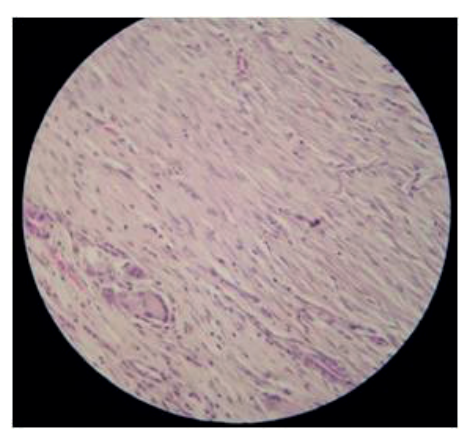

B
FIGURE 3 - Photomicrograph of repair tissue of rat skin - 14 days postoperatively. A. Carbon dioxide group; B. Control group (H\&E, 40x). Greater amount of neovessels in $\mathbf{A}$ (arrow).

\section{Discussion}

The present study investigated the possible effect of controlled subcutaneous injection of $\mathrm{CO}_{2}$ as an experimental procedure on wounds induced on the back of rats. According to available literature, $\mathrm{CO}_{2}$ therapy is a biocompatible treatment, which is easy to perform, has properties of neoangiogenesis and tissue repair, and contributes to healing in animal models and humans.

The increase in $\mathrm{CO}_{2}$ tissue concentration in the microcirculation, caused by controlled injection of this gas, leads to a reduction in $\mathrm{pH}$ and an immediate increase in oxygen availability to tissues through the Bohr effect. As a final consequence of the 
reduction in $\mathrm{pH}$ and the release of mediators, vasomotor effects on the microcirculation, neoangiogenesis and fibrogenesis in the extracellular matrix are observed ${ }^{4,9}$. Ito et al. ${ }^{5}$ using $\mathrm{CO}_{2}$ percutaneously, provided experimental support for the clinical use of $\mathrm{CO}_{2}$-enriched water bathing in the treatment of skin circulatory disorders and ulcers.

According to Piazzolla $a t$ al. $^{4}$, in a preliminary experience with carbon dioxide therapy in the treatment of pressure ulcers in a bedridden elderly patient, this treatment is especially beneficial for elderly adults with pressure ulcers due to immobility because they may have injections at home, avoiding hospitalization.

Abramo and Teixeira ${ }^{9}$ administered $\mathrm{CO}_{2}$ therapy by subcutaneous injection in 10 patients with chronic venous ulcers of the lower limbs, with a mean ulcer duration of 12.5 months. The authors used a 72-hour interval between $\mathrm{CO}_{2}$ application sessions, similar to what was proposed in our study. Although the authors found no significant reduction in wound dimensions, all wounds showed increased numbers of macrophages and fibroblasts and improved granulation tissue after treatment.

Those and other studies supporting the efficacy of $\mathrm{CO}_{2}$ therapy have used this treatment in patients with chronic ulcers, especially ulcers due to venous insufficiency. Such results are best explained by the effect of $\mathrm{CO}_{2}$ therapy on clinical conditions or diseases that involve, in their pathophysiology, tissue hypooxygenation ${ }^{9}$. These conditions differ from those investigated in this study, which analyzed acute ulcers induced in healthy animals. This may explain the discordant results, since there was no statistical significance when comparing wound area reduction and histopathological parameters between the group receiving $\mathrm{CO}_{2}$ therapy and untreated control animals. Furthermore, despite using the same treatment, a discrepancy between the results obtained in chronic ulcers, of any etiology, and those in acute ulcers is expected, since the latter have a different microenvironment and healing pattern. Differences at the level of proinflammatory cytokines, proteases, cell mitosis and growth factors between a healing ulcer and difficult-to-heal ulcers emphasize the need for specific therapies for each type of wound ${ }^{14}$.

In the present study, the animals receiving $\mathrm{CO}_{2}$ therapy showed greater neovascularization than controls, although without statistical significance. In agreement with this observation, Wollina et $a l .{ }^{10}$, studying patients with chronic ulcers of different origin and patients with acute surgical wounds undergoing $\mathrm{CO}_{2}$ therapy, found clinical evidence of improvement in granulation, even in acute ulcers. Other studies have also highlighted the neoangiogenic properties of $\mathrm{CO}_{2}$ therapy, even proposing the involvement of vascular endothelial growth factor (VEGF) and nitric oxide (NO) formation in this mechanism ${ }^{15}$.

Nevertheless, further studies involving a larger sample of animals are warranted to clarify the beneficial effect of $\mathrm{CO}_{2}$ therapy on acute ulcers. Serial wound biopsies may also be used in order to evaluate the effect of $\mathrm{CO}_{2}$ therapy on each developmental phase of wound healing.

\section{Conclusion}

Carbon dioxide therapy had no effects on the healing of acute skin wounds induced in rats.

\section{References}

1. Mendonça RJ, Coutinho-Netto J. Aspectos celulares da cicatrização. An Bras Dermatol. 2009;84(3):257-62.

2. Werner S, Grose R. Regulation of wound healing by growth factors and cytokines. Physiol Rev. 2003;83(3):835-70.

3. Velnar T, Bailey T, Smrkolj V. The wound healing process: an overview of the cellular and molecular mechanisms. J Int Med Res. 2009;37(5):1528-42.

4. Piazzolla LP, Louzada LL, Scoralick FM, Martins, ME, de Sousa, JB. Preliminary experience with carbon dioxide therapy in the treatment of pressure ulcers in a bedridden elderly patient. J Am Geriatr Soc. 2012;60(2):378-9.

5. Ito T, Moore JI, Koss MC. Topical application of $\mathrm{CO}_{2}$ increases skin blood flow. J Invest Dermatol. 1989;93(2):259-62.

6. Brandi C, D'Aniello C, Grimaldi L, Caiazzo E, Stanghellini E. Carbon dioxide therapy: effects on skin irregularity and its use as a complement to liposuction. Aesthetic Plast Surg. 2004;28(4):222-5.

7. Brandi C, D'Aniello C, Grimaldi L, Bosi B, Dei I, Lattarulo P, Alessandrini C. Carbon dioxide therapy in the treatment of localized adiposities: clinical study and histopathological correlations. Aesthetic Plast Surg. 2001;25(3):170-4.

8. Nach R, Zandifar H, Grupta R, Hamilton JS. Subcutaneous carboxytherapy injection for aesthetic improvement of scars. Ear Nose Throat J. 2010;89(2):64-6.

9. Abramo AC, Teixeira TT. Carboinsuflação em úlceras crônicas de membros inferiores. Rev Bras Cir Plast. 2011;26(2):205-10.

10. Wollina U, Heinig B, Uhlemann C. Transdermal $\mathrm{CO}_{2}$ application in chronic wounds. Int J Low Extrem Wounds. 2004;3(2)103-6.

11. Oliveira MVM, Brandão AM, Morais PHA, Silva NG, Silva SM, Carneiro FP, Sousa JB. Effects of bromopride on abdominal wall healing with induced peritoneal sepsis after segmental colectomy and colonic anastomosis in rats. Acta Cir Bras. 2011;26(6):433-7.

12. Melo VA, Anjos DCS, Albuquerque Júnior R, Melo DB, Carvalho FUR. Effect of low level laser on sutured wound healing in rats. Acta Cir Bras. 2011;26(2):129-34.

13. Silva NG, Brandão AM, Oliveira MVM, Morais PHA, Silva SM, Carneiro FP, Sousa JB. Influence of metoclopramide on abdominal wall healing in rats subjected to colonic anastomosis in the presence of peritoneal sepsis induced. Acta Cir Bras. 2011;26(Supl 2):92-9.

14. Trengove NJ, Bielefeldt-Ohmann H, Stacey MC. Mitogenic activity and cytokine levels in non-healing and healing chronic leg ulcers. Wound Repair Regen. 2000;8(1):13-25.

15. Irie H, Tatsumi T, Takamiya M, Zen K, Takahashi T, Azuma A, Tateishi K, Nomura T, Hayashi H, Nakajima N, Okigaki M, Matsubara H. Carbon dioxide-rich water bathing enhances collateral 
blood flow in Ischemic hindlimb via mobilization of endothelial progenitor cells and activation of NO-cGMP system. Circulation. 2005;111(12):1523-9.

\section{Correspondence:}

João Batista de Sousa

Universidade de Brasília

Campus Universitário Darcy Ribeiro-Faculdade de Medicina

Laboratório de Cirurgia Experimental

70910-900 Brasília - DF Brasil

Tel.: (55 61)9984-2845

sousajb@unb.br

Received: January 23, 2013

Review: March 21, 2013

Accepted: April 22, 2013

Conflict of interest: none

Financial source: none

${ }^{1}$ Research performed at Experimental Surgery Laboratory, School of Medicine, University of Brasilia (UnB), Brazil. 